Provided for non-commercial research and education use. Not for reproduction, distribution or commercial use.

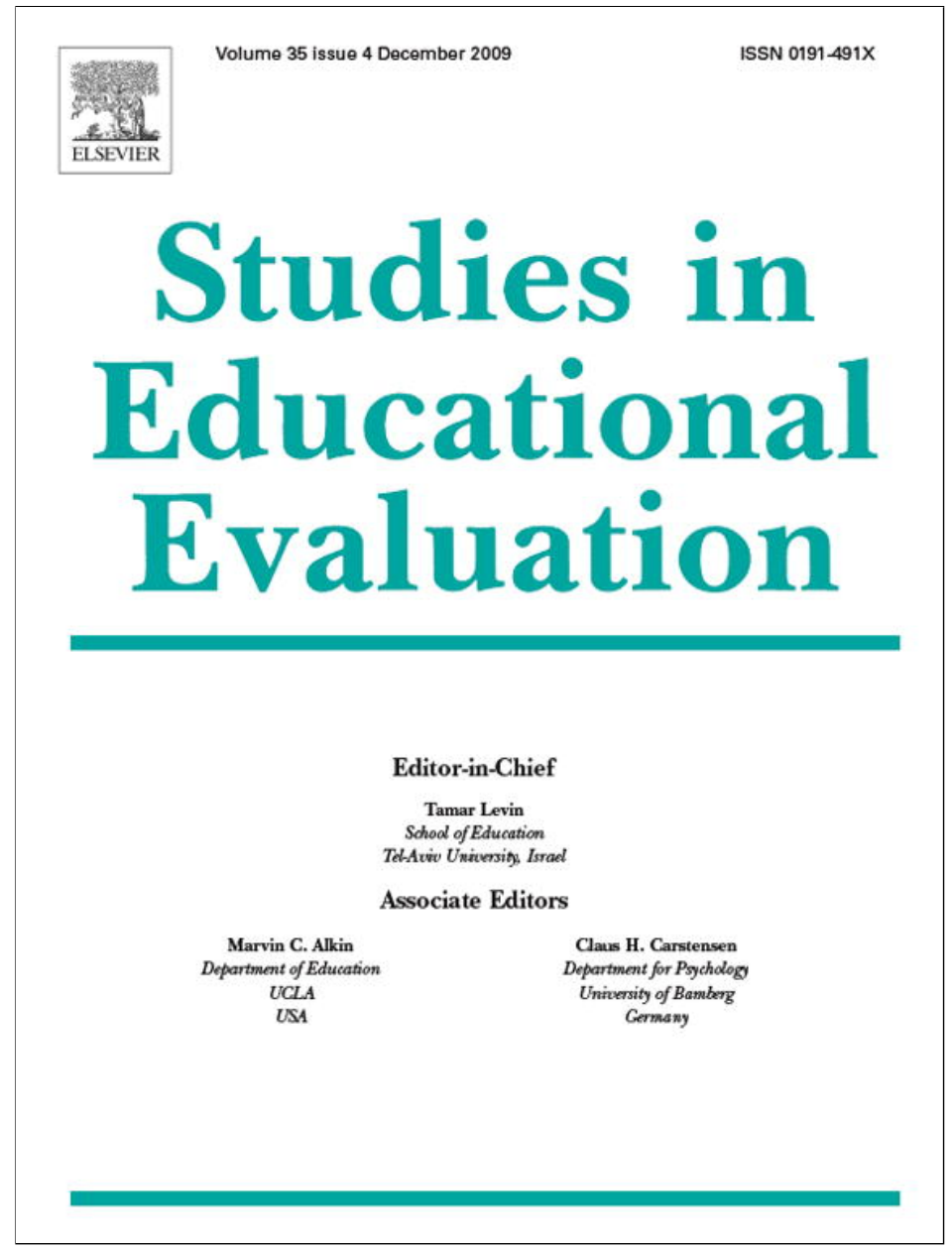

This article appeared in a journal published by Elsevier. The attached copy is furnished to the author for internal non-commercial research and education use, including for instruction at the authors institution and sharing with colleagues.

Other uses, including reproduction and distribution, or selling or licensing copies, or posting to personal, institutional or third party websites are prohibited.

In most cases authors are permitted to post their version of the article (e.g. in Word or Tex form) to their personal website or institutional repository. Authors requiring further information regarding Elsevier's archiving and manuscript policies are encouraged to visit:

http://www.elsevier.com/copyright 


\title{
The effects of different standard setting methods and the composition of borderline groups: A study within a law curriculum
}

\author{
Filip Dochy*, Eva Kyndt, Marlies Baeten, Sofie Pottier, Marlies Veestraeten, K.U. Leuven \\ Centre for Research on Professional Development, Corporate Training and Lifelong Learning, Belgium
}

A R T I C L E I N F O

\section{Keywords:}

Student evaluation

Standard setting methods

Composition borderline group

\begin{abstract}
A B S T R A C T
The aim of this study was to examine the effect of different standard setting methods on the size and composition of the borderline group, on the discrimination between different types of students and on the types of students passing with one method but failing with another. A total of 107 university students were classified into 4 different types of students and completed two examinations. Nine different methods to determine cut scores were applied. Results show that size and composition of the borderline group differed for the different standard setting methods. Results also indicate that it is difficult or even impossible to point out one method across tests as the most appropriate one in terms of discriminating between different students. Situation characteristics such as type and level of difficulty of the test are important determinants when a particular standard setting method has to be chosen.
\end{abstract}

(c) 2010 Published by Elsevier Ltd.
Students have been confronted with grades for a long time. Testing students, scoring results (Jonsson \& Svingby, 2007) or assigning grades, has always been an important component of the educational process (Birenbaum et al., 2006). To make evaluation possible, a standard is used to determine someone's level of competence or knowledge. A major issue to determine a student's progress remains the cut-off point. A point where a student is judged as qualified to graduate, the minimum test score that is an operationalization of the performance standard. Cizek (1996) defines a cut-off point as the passing score which is the lowest score that permits the examinee to be considered competent, to receive a license or credential, to gain admission, etc. It is a concrete translation of the norm used to secure certain quality aspects of education.

However, the field of standard setting is not without controversy. Zieky (2001) stated that there is no such thing as a true cut-off point. Likewise, Kane (1994) stated: "There is no gold standard. There is not even a silver standard" (Kane, 1994, p. 448449). Different standard setting methods tend to lead to different cut-off points (Jaeger, 1989; Zieky, 2001), which have direct consequences for the individual students. Some students fail with one method but pass with another, which leads to the assumption that certain students wrongfully fail or wrongfully pass. Therefore, it is important to investigate the different standard setting

\footnotetext{
* Corresponding author at: Centre for Research on Professional Development, Corporate Training and Lifelong Learning, University of Leuven, Dekenstraat 2 - Box 3772, 3000 Leuven, Belgium. Tel.: +32 163257 08; fax: +32 16325736 .

E-mail address: Filip.Dochy@ped.kuleuven.be (F. Dochy).
}

methods and their properties, and to determine which method is the most appropriate for a certain situation or test. As different components of the learning process should be tuned to one another, the standard setting method should fit the test (Jaeger, 1989; Zieky, 2001).

\section{Theoretical background: standard setting methods}

Standard setting methods can be classified following the distinction established by Dousma and Horsten (1989). There are three main categories of standard setting methods. The first category concerns the absolute methods or standardisations based on the learning material. According to these methods, the teacher determines in advance a minimum expected mastery level. The second category includes the relative methods or standardisations based on the group results where the cut score is calculated after knowing the group results. The third category refers to the standardisations based on an external criterion, for example a limited number of available places for a training. The examiner or student group do not have an influence on this criterion, it is usually predetermined by funding or facilities (Dousma \& Horsten, 1989; Dousma, Horsten, \& Brants, 1997).

The current study incorporates the categories of absolute methods and that of relative methods and adds mixed methods as a third category. The mixed methods act as a compromise between the absolute and relative view. It combines an absolute cut-off point with a relative reference point. The performance of the highest scoring student is used to determine the cut score (CohenSchotans, Van der Vleuten, \& Bender, 1996), not the maximum score possible. According to Beuk (1984) a standard setting method 
should take the required knowledge into account, the absolute information, as well as the relative performance or relative information of a student.

These three groups of standard setting methods comprise various operationalisations of which some are described next. Thereafter, the typology of students which is used in this study is explained.

\section{Absolute methods}

\section{Fixed knowledge percentage}

The minimum result required to pass the test has been defined and decided by the teacher prior to the test. In practice, especially the $50 \%$ cut-off is used and therefore referred to as the common method. The cut-off point is a product of the fixed knowledge percentage and the maximum score. However, in multiple-choice tests the probability of guessing has not been taken into account through this method. Therefore, in this case, the cut score should be calculated as a product of the fixed knowledge percentage and the obtained score with the addition of the probability of guessing if applicable (Van de Watering, 1999).

\section{The core item method of De Groot (1964)}

Specific items of the test are selected as 'core items' which refer to the essence of the subject material and only one answer can be evaluated as the correct one. The level of difficulty has been determined in such a way that the acceptable qualified student will know the correct answer whereas the unqualified student will not. After examining the students, all items go through a "quality analysis" to determine and delete poorly performing items. For every item a $p$-value is calculated which refers to the average percentage of good answers, and which represents the upper limit; the average percentage of wrongly answered questions or in the case of a multiple-choice test the average percentage of answers that have been corrected for guessing, represent the lower limit. The cut-off point is situated within this interval, usually the centre. The percentage of students that pass based on the core items are then applied to the test in general (Van de Watering, 1999).

\section{The method of Ebel $(1965,1972)$}

Prior to the test, items are situated on two dimensions: relevance and difficulty. For every combination of the categories of these two dimensions, for instance very difficult and essential, the percentage of representation of this type of item in the test is calculated. Next, the average proportion of good answers that the teacher expects from a student on the border of passing is given for each combination of the two dimensions. However, if applicable, the effect of guessing should be taken into account by adding the probability score of guessing to the proportion of good answers by real knowledge. If the real knowledge expected for essential easy items is represented by the symbol $p_{\mathrm{w}}$, then the final value of the proportion of expected good answers corrected for guessing, equals $p_{\mathrm{w}}+\left(1-p_{\mathrm{w}}\right) / a$, with ' $a$ ' referring to the number of alternatives. The term $\left[\left(1-p_{\mathrm{w}}\right) / a\right]$ reflects the probability score on the remaining items (Dousma \& Horsten, 1989; Dousma, Horsten, \& Brants, 1997). Based on the proportion of representation and the proportion of expected good answers, the expected mastery level can be calculated by multiplying the number of items and the proportion of expected good answers for every combination of categories, and adding up these products. The corresponding cut-off point is calculated as a multiplication of the expected mastery level and the maximum score.

\section{The Angoff method (1971)}

Angoff (1971) describes the method as "keeping the hypothetical 'minimally acceptable person' in mind, one could go through the test, item per item, and decide whether such a person could answer correctly each item. If a score of one is given for each item answered correctly by that hypothetical person and a score of zero is given for each item answered incorrectly by that person, the sum of the item scores will equal the raw score earned by the "minimally acceptable person" (Angoff, 1971, p. 514-515). In practice, much variations of this method exist.

The method of Jaeger (1982, 1989; Cizek, 1996) is quite similar to the Angoff method (1971)

Every item is evaluated by a 'judge'. The judge asks himself whether every student should be able to answer the item correctly. If the answer is yes, than the item is defined as an essential item (comparable with the core items of 'De Groot'). Based on the number of essential items, the cut-off point is determined. The items are evaluated by different types of judges such as experts, teachers and directors. For each type of judges a different cut-off criterion is determined. For each group one cut-off score, the median of all 'judges' scores', is calculated. After a comparison of the different cut-off scores, the final cut-off score is achieved by the median of the different evaluations.

The optimized extended-response (OER) standard setting method

This standard setting method, described by Cascallar and Cascallar (2003) can be interpreted as a variant of the Angoff method (1971). The method, further on referred to as the method of Cascallar and Cascallar (2003), focuses on new forms of assessment where complex skills and competences are evaluated, by offering a way to calculate a valid standard. A major difference with the Angoff method is the basic assumption which claims that answers to authentic tests are more comprehensive and detailed then those to multiple-choice tests. As with the Angoff method (1971), a judge needs to keep in mind a group of students. For each question, the number of students expected to receive a particular mark is reported. For instance, when the maximum score of an item or task is six, every judge must make an estimation of the number of students with one, two, three, four, five and six marks on the question. The average estimation of all judges determines the cutoff point per item. This procedure is repeated for every item or task therefore not every item needs to be scored on the same mark. The final cut-off score of the test is achieved by averaging all items (Cascallar \& Cascallar, 2003).

\section{Relative methods}

Grading on the curve is a method described by Ebel (1972) and Downie (1967). It descends from a long American educational tradition where for decades the cut-off score was determined by ordering the test results from high to low scores. For instance, when a class consists of 30 students, the best eight students were getting an $\mathrm{A}$, the next best eight students a $\mathrm{B}$, and so on. Obviously, this is a very arbitrary way to determine whether or not a student has failed a test. However, grading on the curve can be considered as a variant of this method. The cut-off point is calculated as the average test score minus 1.5 times the standard deviation of the test scores $\left(\bar{X}-1.5 S_{x}\right)$. With a normal distribution of scores, an average of approximately $7 \%$ of the students fails.

Similar to the grading on the curve, the method of Wijnen (1971) starts with the average performance of a group but the allowed deviation is calculated differently. The standard measure of error is used as a permissible deviation from the group average. This error, a typical property of the method, has an effect on the reliability of the test. Wijnen (1971) advocates that the standard measure of error is an useful index when one assumes that the interest of the teacher is not limited to the performance of a student on the questions in this test but rather extends to the supposed 
performance of comparable tests. After all, this error is "the estimated standard deviation of obtained scores if any individual is given a large number of tests from a domain" (Nunnally, 1967, p. 220) and is therefore an estimation of variance which one can expect when the same student repeatedly gets similar tests (Wijnen, 1971). The cut-off point is determined in a similar way as with grading on the curve. Wijnen chooses a value of two to determine the last permissible deviation $\left(\bar{X}-2 S_{e}\right)$, before rejecting those students whose score cannot be accepted as a random deviation from the mean. He claims that everyone who is not rejected within a confidence interval of $95 \%$ can be classified in an educational setting as a typical student in a favourable way compared to those that have been rejected (Wijnen, 1971). The reliability of the test is included in the percentage of rejection. This method can be represented as: $\bar{X}-2 S_{e}=\bar{X}-S_{x} \sqrt{\left(1-r_{t t}\right)}$ where $\bar{X}$ refers to the group average. The formula shows that increasing the reliability of the test, increases the percentage of rejected students. Similar to grading on the curve a normal distribution of test scores has been assumed.

\section{Mixed method}

The absolute method with relative reference point described by Cohen-Schotans et al. (1996) suggests an absolute cut-off but with a relative reference point. Instead of using the maximum score as a reference, it is based on the performance of students with the highest scores. One possible option for its application is taking the total score of the cumulative proportion of $95 \%$ to determine the cut-off point. In addition to this relative point of reference, an absolute criterion must be determined such as the requirement that a thorough understanding of a minimum of $60 \%$ of the subject matter is expected. The chosen percentages are preferences of the teacher. The cut-off point is determined by the score of the highest scoring students (for example those in the 95 percentile) corrected for the probability of guessing. The calculation can be done as follows: Cut-off point $=$ absolute criterion $\times$ (relative reference point - probability score)+ probability score. This probability score equals the number of multiple-choice questions divided by the number of alternatives.

\section{Student types}

In order to investigate the effects of standard setting methods on the discrimination between different types of students, we investigated typologies that differentiate between competent and less competent students. A recent typology was developed by Van de Watering (2006). He investigated the differences between tutors' perceptions of learning performance and the actual performances of their students. The typology consists of four different student types that usually are detected after careful observation of students in classes, meetings and discussions by different teachers, and can be described as follows:

Type I student. This type represents the barely competent student. They are not at all, or not sufficiently, prepared for the study group meetings. Participation in group discussions is minimal and contributions are in general not very useful and contain little useful information. They are only interested in that what will be asked in the assessment. These students participate in the group meeting mainly for the social benefits. In practice, one distinguishes two sets of type I students: those with little motivation and those with little capacity (Van de Watering, 2006).

Type II student. This type of student represents the moderately competent student and can be characterised as the average student. Preparation for group meetings is usually sufficient.
These students need extra teaching and teachers can easily predict for which subjects this extra teaching is required, specifically the more difficult subjects. They have sufficient confidence in their abilities but encounter problems in switching from one subject to another. They do not pressure themselves in studying the required materials (Van de Watering, 2006).

Type III student. This type of students represents the highly competent, cognitively very strong, student. These students are able to keep a view of the bigger picture, can distinguish between the main subjects and subjects of lesser importance and check themselves whether or not they have understood the subjects. These students consult sources that go beyond the prescribed materials. They feel at home in the study group and take responsibility in guiding the discussion in the study group. They enjoy explaining subjects to their fellow students, or exchanging information and sources. They are relaxed in studying the required material. Teachers characterise these students as adaptive, flexible and cognitively strong students who have made a conscious choice for university and this specific study (Van de Watering, 2006).

Type IV student. This type of student prepares for study group meetings and has written out most of the preparation. During discussions, however, they try to maintain a low profile. When these students are encouraged to do so, they can get to the core of the problem quickly and can contribute in a useful manner. These students are extremely interested in the solutions of other students. They gather all the information that is discussed in the study group, even if this information is not directly relevant for the core of the subject at hand. This type of student has the feeling that they have to study everything. They invest a lot of time without gaining confidence or mastering the subject. They cannot easily distinguish between the core and side issues. Teachers characterise these students as moderately or highly competent but their performance in the study group is characterised by insecurity and forced behaviour. Teachers see them as inflexible and not very adaptive (Van de Watering, 2006).

\section{The present study}

The present study investigates the effects of different standard setting methods on the size and composition of borderline groups of students, and the number of failing students. Previous comparisons of different standard setting methods have indicated that different methods indeed result in different cut-off points and consequently in different number of students qualified to pass (Van de Watering, 1999; Van de Watering \& Van der Rijt, 2006; Van de Watering \& van der Rijt, 2003). Therefore borderline group students become the most important group of students to scrutinise and determine the cut-off point. The standard deviation of the test and a $95 \%$ confidence interval were used to filter only those students whose border position was not determined by an error of estimation but rather by a valid and reliable cause. The borderline group consists of students that score within the interval: cut score $\pm 2 S_{e}=$ cut score $\pm S x \sqrt{ }\left(1-r_{t t}\right), S_{x}$ refers to the standard deviation of the group results, $S_{e}$ to the standard deviation of error and $r_{t t}$ refers to the reliability of the study test.

As mentioned before, the typology of Van de Watering (2006) is used to distinguish several student types. Moreover, this study looks into the effects of several standard setting methods on the discrimination between different types of students, and on the types of students passing with one method but failing with another. We want to verify whether there is one single standard setting method that discriminates best between the different types of student. The research questions addressed in this study are: 
- Are there differences in the size of the borderline group when using different standard setting methods?

- Are there differences in the composition of the borderline group regarding type of students and number of failing students when using different standard setting methods?

- What is the size and composition of the group of students who pass with one standard setting method but fail with another?

- Which standard setting method discriminates best between the different types of students?

\section{Method}

\section{Participants}

The participants in this study were first-year bachelor students in the law program at a university. In this program, lessons are given to study groups of 14-19 students. The students were enrolled in a modular program which consisted of four courses with a test at the end of each course of which two tests were selected for comparison; the most difficult one and the easiest one (based on the $p$-values for passing). The sample, randomly drawn from all the examinees at the end of the course, consisted of 107 students (56 female and 51 male students). A total of 92 and 99 students took test one and two, respectively. Before the last test two teachers who were coaching and supervising the study groups were asked to classify the 107 students of the sample into the four different student types (Table 1). This classification was based on observations in group and assignment discussions, preparations of educational group meetings and their study progress. The interrater reliability equalled 0.95 .

Van de Watering (2006), investigating the same students, performed a $t$-test for an independent sample conducted with the data of test 4, which showed that students from the sample have a similar average as all the 360 students following the course and which were not drawn for the sample. The research of Claessens and Van de Watering (2003) also showed that the test results were course independent. This suggests that results are from a representative sample, and thus it is possible to generalize to all four courses.

Tests

The two examined courses are Test 1: 'Introduction', and Test 2: 'Law actions'. The maximum score of each test was fifty points: forty points on a multiple-choice test, each item having four alternative responses, and ten points on open-ended questions. An item analysis was performed to confirm the quality of the questions in the two tests. All questions were kept in the analysis.

To investigate the level of difficulty of the tests, the $p$-values of the different tests were calculated. The $p$-values, representing the chance for success, of both Test $1(p=0.63)$ and Test $2(p=0.52)$ were within the range of an 'on average difficult' test $(0.4<p<0.8)$. The non-parametric bilateral Kolmogorov-Smirnov test for two independent samples was used to examine the significance of differences in level of difficulty. A significant level of difference was found between the two tests $(Z=1.767, p=0.004)$.

Table 1

Number of students for every student type.

\begin{tabular}{lllllc}
\hline & Type I & Type II & Type III & Type IV & Total \\
\hline Total sample & 19 & 38 & 24 & 26 & 107 \\
Test 1 & 17 & 31 & 21 & 23 & 92 \\
Test 2 & 17 & 34 & 23 & 25 & 99 \\
\hline
\end{tabular}

\section{Analysis}

In order to answer the research questions descriptive statistics were calculated. For both tests the cut-off points and the descriptive statistics of the borderline group (size, type of students, and number of failing students) resulting from each standard setting method are calculated. The average test scores are calculated to determine the most appropriate standard setting method.

\section{Results}

The results will be presented by research question. For the first question "Are there differences in the size of the borderline group when using different standard setting methods?" the results show a clear indication of differences in cut-off points between different standard setting methods. For both tests, a clear difference was observed between the absolute methods and relative methods with a higher cut-off point resulting when using the former. For Test 1 a lower cut-off score was observed when using the common method than with other absolute methods. For both tests the mixed method can be situated in between. The mixed method for Test 2 has a cut-off point close to that of a number of absolute methods: the common method, the method of De Groot (1964) and the method of Cascallar and Cascallar (2003).

The different cut-off points for the different standard setting methods consequently lead to differences between these methods regarding size of the borderline group (see Table 2). Test 1 shows a rather equal size of borderline group for all absolute methods with the exception of the common method, which has a much smaller borderline group. The common method compares, regarding size of the borderline group, better with the relative methods. However, the small borderline group when using grading on the curve is remarkable. The borderline group size for the mixed method is situated between those of the absolute and the relative methods. For Test 2 the size of the borderline group differs for every cut-off provision method. However, no unequivocal clear difference can be observed between absolute, relative and mixed methods. Only grading on the curve has a much smaller borderline group than the other methods. Across tests relatively large differences are noticeable in the size of borderline groups when using the same method.

The second research question "Are there differences in the composition of the borderline group regarding type of students and number of failing students when using different standard setting methods?" showed the following results. Regarding the type of borderline students, Test 1 shows a quite similar distribution for all standard setting methods (see Table 3): type II students are represented the most, followed by type IV, type III and finally type I. The common method is an exception; here type II students are represented the least in the borderline group. These findings could have been expected since type II and IV students are typed as 'norm' students which means that they are expected to score within the range of the borderline group (Van de Watering, 2006).

Next we looked at the difference for different standard setting methods regarding those students in the borderline group who are failing. For every method, type III students have very low representation in the group of underachievers (see Table 4). For the common method, the method of De Groot (1964), the method of Wijnen (1971) and the mixed method the number of type III students is slightly higher because the group of underachievers in the borderline group for these methods is very small, in absolute numbers there are still very few type III students failing. Most type III students within the borderline group score above the cut-off point for all methods except for 
Table 2

Cut-off points and borderline group size.

\begin{tabular}{|c|c|c|c|c|}
\hline \multirow[t]{2}{*}{ Method } & \multicolumn{2}{|c|}{ Cut-off point } & \multicolumn{2}{|c|}{ Borderline group size } \\
\hline & Test 1 & Test 2 & Test 1 & Test 2 \\
\hline \multicolumn{5}{|l|}{ Absolute methods } \\
\hline \multirow[t]{2}{*}{ Common method } & 25 & 25 & $16 / 92$ & $40 / 99$ \\
\hline & & & $17.39 \%$ & $40.40 \%$ \\
\hline \multirow[t]{2}{*}{ Fixed knowledge percentage (60\%) } & 30 & 30 & $44 / 92$ & $26 / 99$ \\
\hline & & & $47.8 \%$ & $26.3 \%$ \\
\hline \multirow[t]{2}{*}{ Method of De Groot (1964) } & 28.5 & 25 & $36 / 92$ & $40 / 99$ \\
\hline & & & $39.12 \%$ & $40.4 \%$ \\
\hline \multirow[t]{2}{*}{ Method of Ebel $(1965,1972)$} & 31.5 & 29 & $46 / 92$ & $38 / 99$ \\
\hline & & & $50 \%$ & $38.38 \%$ \\
\hline \multirow[t]{2}{*}{ Method of Jaeger $(1982,1989)$} & 29 & 26 & $40 / 92$ & $45 / 99$ \\
\hline & & & $43.48 \%$ & $45.45 \%$ \\
\hline \multirow{2}{*}{ Method of Cascallar and Cascallar (2003) } & 29.5 & 25 & $42 / 92$ & $40 / 99$ \\
\hline & & & $45.65 \%$ & $40.4 \%$ \\
\hline \multicolumn{5}{|l|}{ Relative methods } \\
\hline \multirow[t]{2}{*}{ Grading on the curve } & 20 & 15 & $7 / 92$ & $10 / 99$ \\
\hline & & & $8 \%$ & $10.1 \%$ \\
\hline \multirow[t]{2}{*}{ Method of Wijnen (1971) } & 26 & 20.5 & $23 / 92$ & $34 / 99$ \\
\hline & & & $25 \%$ & $34.4 \%$ \\
\hline \multicolumn{5}{|l|}{ Mixed method } \\
\hline \multirow[t]{2}{*}{ Absolute method with a relative reference point } & 28 & 24.5 & $32 / 92$ & $42 / 99$ \\
\hline & & & $34.8 \%$ & $42.4 \%$ \\
\hline
\end{tabular}

the common method and the method of Wijnen (1971). Type I students are represented quite well in the underachieving group (between $16.67 \%$ and $36 \%$ ) for all methods, except for grading on the curve. The cut-off point for this method is so low that it is not likely that many students fail. Remarkably, for all methods, except the common method, between $10 \%$ and less than $50 \%$ of the type I students within the borderline group score below the cut score. For type II and type IV students the percentages of students failing are very different for the different methods. In general, approximately $50 \%$ of the type II students from the borderline group score below the cut score, except for the method of Wijnen (1971) where not one type II student scores below that level. Type IV students score between 11\% and 50\% under the cut score, except for grading on the curve where not one type IV student fails, probably because of the very low cut score. The typing of these students as 'norm' students (Van de
Watering, 2006) fits the profile very well since their scores are well distributed around the cut-off point.

For the second test, the big difference between type I and type III students when using absolute or relative methods is remarkable (see Table 5). The mixed method has similar results as the absolute methods. When an absolute or mixed method is used, type I students are the least represented, while with the relative methods they are much more represented (between 21\% and 50\%). When the absolute and mixed methods are used, type III students are reasonably represented in the borderline group (around 25\%), with the exception of the method of Jaeger according to which $16.67 \%$ of the type III students are represented in the borderline group. For the relative method, on the other hand, the number of type III students is negligible. The percentages of type II and type IV students in the borderline groups are comparable to each other, with the exception of grading on the curve which could be caused by

Table 3

Composition borderline group for test 1 .

\begin{tabular}{|c|c|c|c|c|c|c|}
\hline \multirow{2}{*}{$\frac{\text { Test } 1}{\text { Methods }}$} & \multirow[t]{2}{*}{ Range borderline group } & \multirow{2}{*}{$\frac{\text { Number of borderline students }}{\text { Total }}$} & \multicolumn{4}{|c|}{ Composition borderline group } \\
\hline & & & Type I & Type II & Type III & Type IV \\
\hline \multicolumn{7}{|l|}{ Absolute methods } \\
\hline \multirow[t]{2}{*}{ Common method } & $21.6 \leq x \leq 28.4$ & 16 & 4 & 3 & 4 & 5 \\
\hline & & & $25 \%$ & $18.75 \%$ & $25 \%$ & $31.25 \%$ \\
\hline \multirow[t]{2}{*}{ Fixed knowledge percentage } & $26.6 \leq x \leq 33.4$ & 44 & 12 & 15 & 6 & 11 \\
\hline & & & $27.27 \%$ & $34.09 \%$ & $13.64 \%$ & $25 \%$ \\
\hline \multirow[t]{2}{*}{ Method of De Groot (1964) } & $25.1 \leq x \leq 31.9$ & 36 & 11 & 12 & 3 & 10 \\
\hline & & & $30.56 \%$ & $33.33 \%$ & $8.33 \%$ & $27.78 \%$ \\
\hline \multirow[t]{2}{*}{ Method of Ebel $(1965,1972)$} & $28.1 \leq x \leq 34.9$ & 46 & 11 & 16 & 7 & 12 \\
\hline & & & $23.91 \%$ & $34.78 \%$ & $15.21 \%$ & $26.09 \%$ \\
\hline \multirow[t]{2}{*}{ Method of Jaeger $(1982,1989)$} & $25.6 \leq x \leq 32.4$ & 40 & 12 & 14 & 4 & 10 \\
\hline & & & $30 \%$ & $35 \%$ & $10 \%$ & $25 \%$ \\
\hline \multirow[t]{2}{*}{ Method of Cascallar and Cascallar (2003) } & $26.1 \leq x \leq 32.9$ & 42 & 12 & 14 & 5 & 11 \\
\hline & & & $28.57 \%$ & $33.33 \%$ & $11.9 \%$ & $26.19 \%$ \\
\hline \multicolumn{7}{|l|}{ Relative methods } \\
\hline \multirow[t]{2}{*}{ Grading on the curve } & $16.6 \leq x \leq 23.4$ & 7 & 2 & 3 & 1 & 1 \\
\hline & & & $28.57 \%$ & $42.86 \%$ & $14.29 \%$ & $14.29 \%$ \\
\hline \multirow[t]{2}{*}{ Method of Wijnen (1971) } & $23.1 \leq x \leq 29.9$ & 23 & 7 & 8 & 3 & 5 \\
\hline & & & $30.43 \%$ & $34.78 \%$ & $13.04 \%$ & $21.74 \%$ \\
\hline \multicolumn{7}{|l|}{ Mixed method } \\
\hline \multirow[t]{2}{*}{ Absolute method with a relative reference point } & $24.6 \leq x \leq 31.4$ & 32 & 10 & 11 & 2 & 9 \\
\hline & & & $31.25 \%$ & $34.38 \%$ & $6.25 \%$ & $28.13 \%$ \\
\hline
\end{tabular}


Table 4

Composition failing students in the borderline group per method for test 1 .

\begin{tabular}{|c|c|c|c|c|c|c|}
\hline \multirow{2}{*}{$\begin{array}{c}\text { Test } 1 \\
\text { Methods }\end{array}$} & \multirow[t]{2}{*}{ Range failing scores } & \multirow{2}{*}{$\begin{array}{l}\text { Number of failing } \\
\text { borderline students } \\
\text { Total }\end{array}$} & \multicolumn{4}{|c|}{$\begin{array}{l}\text { Composition failing students in the } \\
\text { borderline group per method }\end{array}$} \\
\hline & & & Type I & Type II & Type III & Type IV \\
\hline \multicolumn{7}{|l|}{ Absolute methods } \\
\hline Common method & $21.6 \leq x \leq 25$ & 9 & $\begin{array}{c}3 \\
33.33 \%\end{array}$ & $\begin{array}{c}1 \\
11.11 \%\end{array}$ & $\begin{array}{c}3 \\
33.33 \%\end{array}$ & $\begin{array}{c}2 \\
22.22 \%\end{array}$ \\
\hline Fixed knowledge percentage & $26.6 \leq x \leq 30$ & 15 & $\begin{array}{c}5 \\
33.33 \%\end{array}$ & $\begin{array}{r}6 \\
40 \%\end{array}$ & $\begin{array}{l}1 \\
6.67 \%\end{array}$ & $\begin{array}{r}3 \\
20 \%\end{array}$ \\
\hline Method of De Groot (1964) & $25.1 \leq x \leq 28.5$ & 6 & $\begin{array}{c}1 \\
16.67 \%\end{array}$ & $\begin{array}{c}2 \\
33.33 \%\end{array}$ & $\begin{array}{c}1 \\
16.67 \%\end{array}$ & $\begin{array}{c}2 \\
33.33 \%\end{array}$ \\
\hline Method of Ebel $(1965,1972)$ & $28.1 \leq x \leq 31.5$ & 25 & $\begin{array}{r}9 \\
36 \%\end{array}$ & $\begin{array}{r}9 \\
36 \%\end{array}$ & $\begin{array}{r}1 \\
4 \%\end{array}$ & $\begin{array}{r}6 \\
24 \%\end{array}$ \\
\hline Method of Jaeger $(1982,1989)$ & $25.6 \leq x \leq 29$ & 11 & $\begin{array}{l}2 \\
18.18 \%\end{array}$ & $\begin{array}{l}6 \\
54.55 \%\end{array}$ & $\begin{array}{l}1 \\
9.09 \%\end{array}$ & $\begin{array}{c}2 \\
18.18 \%\end{array}$ \\
\hline Method of Cascallar and Cascallar (2003) & $26.1 \leq x \leq 29.5$ & 13 & $\begin{array}{c}4 \\
30.77 \%\end{array}$ & $\begin{array}{l}5 \\
38.46 \%\end{array}$ & $\begin{array}{l}1 \\
7.69 \%\end{array}$ & $\begin{array}{c}3 \\
23.08 \%\end{array}$ \\
\hline \multicolumn{7}{|l|}{ Relative methods } \\
\hline Grading on the curve & $16.6 \leq x \leq 20$ & 1 & $\begin{array}{r}0 \\
0 \%\end{array}$ & $\begin{array}{r}1 \\
100 \%\end{array}$ & $\begin{array}{r}0 \\
0 \%\end{array}$ & $\begin{array}{r}0 \\
0 \%\end{array}$ \\
\hline Method of Wijnen (1971) & $23.1 \leq x \leq 26$ & 6 & $\begin{array}{c}2 \\
33.33 \%\end{array}$ & $\begin{array}{r}0 \\
0 \%\end{array}$ & $\begin{array}{c}2 \\
33.33 \%\end{array}$ & $\begin{array}{c}2 \\
33.33 \%\end{array}$ \\
\hline $\begin{array}{l}\text { Mixed method } \\
\text { Absolute method with a relative reference point }\end{array}$ & $24.6 \leq x \leq 28$ & 5 & $\begin{array}{r}1 \\
20 \%\end{array}$ & $\begin{array}{r}2 \\
40 \%\end{array}$ & $\begin{array}{r}1 \\
20 \%\end{array}$ & $\begin{array}{r}1 \\
20 \%\end{array}$ \\
\hline
\end{tabular}

the fact that this method has a relatively small borderline group $(n=10)$. A small absolute difference becomes a large difference in terms of percentages. Type II and type IV students are well represented with all methods. Again we can conclude that these 'norm' students largely score within the range of the borderline group.

For all methods, except the relative methods, type I students are represented the lowest within the underachieving group of borderline students (see Table 6). With the relative methods, the number of type I students is somewhat higher, because the group of underachievers within the borderline group is very small. When using an absolute method about half or more of the borderline students score below the cut score. The second smallest group of underachievers is the type III student. These students are expected to score above the cut-off. However, about $50 \%$ of the type III students in the borderline group score below the cut score.
Type II or type IV students are approximately equally represented in the underachieving group for all methods, except for the method grading on the curve, but with this method there is only one student failing because of the extreme low cut-off point.

Regarding the third research question "What is the size and composition of the group of students who pass with one standard setting method but fail with another?', it was found that a student with a score of 31.5 or more passes with every method, a student with a score of 19.5 or less fails with every method. However, 48 of the 92 students ( $>50 \%$ ) pass or fail depending on the used method. These students, with a score between 20 and 31, are $82.35 \%$ of the participating type I students, $41.94 \%$ of the type II students, $23.8 \%$ of the type III students and $47.83 \%$ of the type IV students.

For Test 2, a student with a score of 30 or more passes with every method, a student with a score of 14.5 or less, fails with every method. However, 81 students of 99 students $( \pm 82 \%)$ pass with one

Table 5

Composition borderline group for test 2 .

\begin{tabular}{|c|c|c|c|c|c|c|}
\hline \multirow{2}{*}{$\frac{\text { Test } 2}{\text { Methods }}$} & \multirow[t]{2}{*}{ Range borderline group } & \multirow{2}{*}{$\frac{\text { Number of borderline students }}{\text { Total }}$} & \multicolumn{4}{|c|}{ Composition borderline group } \\
\hline & & & Type I & Type II & Type III & Type IV \\
\hline \multicolumn{7}{|l|}{ Absolute methods } \\
\hline Common method & $21.7 \leq x \leq 28.3$ & 40 & $\begin{array}{r}6 \\
15 \%\end{array}$ & $\begin{array}{r}14 \\
35 \%\end{array}$ & $\begin{array}{c}9 \\
22.5 \%\end{array}$ & $\begin{array}{l}11 \\
27.5 \%\end{array}$ \\
\hline Fixed knowledge percentage & $26.7 \leq x \leq 33.3$ & 26 & $\begin{array}{c}3 \\
11.54 \%\end{array}$ & $\begin{array}{l}10 \\
38.46 \%\end{array}$ & $\begin{array}{c}7 \\
26.92 \%\end{array}$ & $\begin{array}{c}6 \\
23.08 \%\end{array}$ \\
\hline Method of De Groot (1964) & $21.7 \leq x \leq 28.3$ & 40 & $\begin{array}{r}6 \\
15 \%\end{array}$ & $\begin{array}{r}14 \\
35 \%\end{array}$ & $\begin{array}{c}9 \\
22.5 \%\end{array}$ & $\begin{array}{l}11 \\
27.5 \%\end{array}$ \\
\hline Method of Ebel $(1965,1972)$ & $25.7 \leq x \leq 32.3$ & 31 & $\begin{array}{c}4 \\
12.9 \%\end{array}$ & $\begin{array}{l}11 \\
35.48 \%\end{array}$ & $\begin{array}{c}8 \\
25.81 \%\end{array}$ & $\begin{array}{c}8 \\
25.81 \%\end{array}$ \\
\hline Method of Jaeger $(1982,1989)$ & $22.7 \leq x \leq 29.3$ & 45 & $\begin{array}{c}5 \\
11.11 \%\end{array}$ & $\begin{array}{l}14 \\
31.11 \%\end{array}$ & $\begin{array}{l}12 \\
16.67 \%\end{array}$ & $\begin{array}{l}14 \\
31.11 \%\end{array}$ \\
\hline Method of Cascallar and Cascallar (2003) & $21.7 \leq x \leq 28.3$ & 40 & $\begin{array}{r}6 \\
15 \%\end{array}$ & $\begin{array}{r}14 \\
35 \%\end{array}$ & $\begin{array}{c}9 \\
22.5 \%\end{array}$ & $\begin{array}{l}11 \\
27.5 \%\end{array}$ \\
\hline \multicolumn{7}{|l|}{ Relative methods } \\
\hline Grading on the curve & $11.7 \leq x \leq 18.3$ & 10 & $\begin{array}{r}5 \\
50 \%\end{array}$ & $\begin{array}{r}1 \\
10 \%\end{array}$ & $\begin{array}{r}0 \\
0 \%\end{array}$ & $\begin{array}{r}4 \\
40 \%\end{array}$ \\
\hline Method of Wijnen (1971) & $17.2 \leq x \leq 23.8$ & 34 & $\begin{array}{c}7 \\
20.59 \%\end{array}$ & $\begin{array}{l}15 \\
44.12 \%\end{array}$ & $\begin{array}{l}3 \\
8.82 \%\end{array}$ & $\begin{array}{c}9 \\
26.47 \%\end{array}$ \\
\hline \multicolumn{7}{|l|}{ Mixed method } \\
\hline Absolute method with a relative reference point & $21.2 \leq x \leq 27.8$ & 42 & $\begin{array}{c}6 \\
14.29 \%\end{array}$ & $\begin{array}{l}15 \\
35.71 \%\end{array}$ & $\begin{array}{l}10 \\
23.81 \%\end{array}$ & $\begin{array}{l}11 \\
26.19 \%\end{array}$ \\
\hline
\end{tabular}


Table 6

Composition failing students in the borderline group per method for test 2 .

\begin{tabular}{|c|c|c|c|c|c|c|}
\hline \multirow{2}{*}{$\begin{array}{c}\text { Test } 2 \\
\text { Methods }\end{array}$} & \multirow[t]{2}{*}{ Range failing scores } & \multirow{2}{*}{$\begin{array}{l}\text { Number of failing } \\
\text { borderline students } \\
\text { Total }\end{array}$} & \multicolumn{4}{|c|}{$\begin{array}{l}\text { Composition failing students in the } \\
\text { borderline group per method }\end{array}$} \\
\hline & & & Type I & Type II & Type III & Type IV \\
\hline \multicolumn{7}{|l|}{ Absolute methods } \\
\hline Common method & $21.7 \leq x \leq 25$ & 21 & $\begin{array}{c}3 \\
14.29 \%\end{array}$ & $\begin{array}{c}7 \\
33.33 \%\end{array}$ & $\begin{array}{l}4 \\
19.05 \%\end{array}$ & $\begin{array}{c}7 \\
33.33 \%\end{array}$ \\
\hline Fixed knowledge percentage & $26.7 \leq x \leq 30$ & 18 & $\begin{array}{l}2 \\
11.11 \%\end{array}$ & $\begin{array}{l}5 \\
27.78 \%\end{array}$ & $\begin{array}{c}5 \\
27.78 \%\end{array}$ & $\begin{array}{l}6 \\
33.33 \%\end{array}$ \\
\hline Method of De Groot (1964) & $21.7 \leq x \leq 25$ & 21 & $\begin{array}{l}3 \\
14.29 \%\end{array}$ & $\begin{array}{l}7 \\
33.33 \%\end{array}$ & $\begin{array}{c}4 \\
19.05 \%\end{array}$ & $\begin{array}{l}7 \\
33.33 \%\end{array}$ \\
\hline Method of Ebel $(1965,1972)$ & $25.7 \leq x \leq 29$ & 17 & $\begin{array}{l}3 \\
17.65 \%\end{array}$ & $\begin{array}{l}6 \\
35.29 \%\end{array}$ & $\begin{array}{c}4 \\
23.53 \%\end{array}$ & $\begin{array}{c}4 \\
23.53 \%\end{array}$ \\
\hline Method of Jaeger $(1982,1989)$ & $22.7 \leq x \leq 26$ & 24 & $\begin{array}{l}2 \\
8.33 \%\end{array}$ & $\begin{array}{c}8 \\
33.33 \%\end{array}$ & $\begin{array}{r}6 \\
25 \%\end{array}$ & $\begin{array}{c}8 \\
33.33 \%\end{array}$ \\
\hline Method of Cascallar and Cascallar (2003) & $21.7 \leq x \leq 25$ & 21 & $314.29 \%$ & $\begin{array}{c}7 \\
33.33 \%\end{array}$ & $\begin{array}{c}4 \\
19.05 \%\end{array}$ & $\begin{array}{c}7 \\
33.33 \%\end{array}$ \\
\hline \multicolumn{7}{|l|}{ Relative methods } \\
\hline Grading on the curve & $11.7 \leq x \leq 15$ & 1 & $\begin{array}{r}1 \\
100 \%\end{array}$ & $\begin{array}{r}0 \\
0 \%\end{array}$ & $\begin{array}{r}0 \\
0 \%\end{array}$ & $\begin{array}{r}0 \\
0 \%\end{array}$ \\
\hline Method of Wijnen (1971) & $17.2 \leq x \leq 20.5$ & 13 & $\begin{array}{c}4 \\
30.77 \%\end{array}$ & $\begin{array}{c}5 \\
38.46 \%\end{array}$ & $\begin{array}{r}0 \\
0 \%\end{array}$ & $\begin{array}{c}4 \\
30.77 \%\end{array}$ \\
\hline \multicolumn{7}{|l|}{ Mixed method } \\
\hline Absolute method with a relative reference point & $21.2 \leq x \leq 24.5$ & 21 & $\begin{array}{l}3 \\
14.29 \%\end{array}$ & $\begin{array}{l}8 \\
38.10 \%\end{array}$ & $\begin{array}{c}4 \\
19.05 \%\end{array}$ & $\begin{array}{c}6 \\
28.57 \%\end{array}$ \\
\hline
\end{tabular}

method but fail with another. This group of students with a score between 15 and 30 represent $88.24 \%$ of the participating type I students, $82.35 \%$ of the type II students, $60.87 \%$ of the type III students and $96 \%$ of the type IV students.

The fourth research question "Which standard setting method discriminates best between the different types of students?" is answered by test. Ideally, type I students, should fail with every method, and type III students should pass with every method. Unfortunately, this is not the case for any of the tests. Many type III students wrongly fail and many type I students wrongly pass, which means there is a relatively large group of false negatives and false positives. However, possible misclassifications of students in a particular student type should be given close consideration. This observation makes us wonder which method is the best method, in terms of distinguishing student types.

To answer this question, not only the borderline group, but the complete group of students was taken into account. For every student type different hypotheses based on Van de Watering (2006) are tested for the different methods: (1) type I students should score as much as possible below the cut-off point, (2) type III students should score as much as possible above the cut-off point, (3) type II and type IV students should score near the cut-off point (average within the borderline group). The method that most closely meets those three criteria is indicated to be the best discriminator. The average test scores used to answer this question can be found in Table 7 .

For the first test, the average of all student types is situated above the cut-off point when using the common method, grading on the curve, method of Wijnen (1971), method of De Groot (1964) and the absolute method with a relative reference point. This means that all types of students generally pass, therefore these methods are

Table 7

Average test scores per student type.

\begin{tabular}{lllll}
\hline & Mean score Test 1 & SD Test 1 & Mean score Test 2 & SD Test 2 \\
\hline Type I & 28.7 & 3.90 & 21.2 & 4.87 \\
Type II & 32.1 & 5.95 & 24.8 & 4.87 \\
Type III & 34 & 4.22 & 29.3 & 4.25 \\
Type IV & 31.8 & 3.66 & 24 & 6.69 \\
\hline
\end{tabular}

not severe enough. However, type I students score only slightly above the cut-off point while type II and type IV students score on the upper limit of the borderline group. For a fixed knowledge percentage (60\%) the averages of type I, type II and type IV students are situated within the borderline group where generally type I students do not pass while type II and type IV students score around the cut-off point. For the method of Ebel $(1965,1972)$ the averages of all types are situated within the borderline group. However, it is a tight fit for type I and type III students where type I students score around the lower limit and type III students around the upper limit. Type I students do not pass on average, while type II and type IV students score around the cut-off and type III students reasonably high above the cut-off. For the method of Jaeger (1982, 1989) and the method of Cascallar and Cascallar (2003), the average of type I, type II and type IV students are situated within the borderline group. In general type I students do not pass while type II and type IV students score slightly above the cut-off point. For all methods type III students score above the cut-off point and the borderline group, except for the method of Ebel where the average is situated just within the borderline group.

For the second test, the average of all types of students lies above the cut-off when using the method grading on the curve and the method of Wijnen (1971), meaning that all types pass on average. Therefore those methods are not harsh enough. For the method fixed knowledge percentage (60\%) the averages of all types are positioned below the cut-off point and only type II students score within the borderline group. Therefore, this method is far too strict. The method of Ebel $(1965,1972)$ is also slightly too harsh, the averages of type I, type II, and type IV students are situated below the cut-off point and even below the borderline group. For the method of De Groot (1964), the averages of type I, II and IV students are situated within the borderline group. In general type I and type IV students score below the cut-off point and type II students score slightly above the cut-off point. The average of type III students is positioned above the borderline group. For the method of Jaeger $(1982,1989)$ the averages of all types, except type I, lie within the borderline group. The average of type I students lies below the range of the borderline group. The averages of type II and type IV students lie below the cut-off point while the average of type III students is positioned just on the upper limit of the borderline 
group, thus above the cut-off. For the absolute method with a relative reference point the average of type I students is situated below the cut-off point. The average of type II and type IV students lie just below the cut-off point but still clearly within the borderline group. Type III students score on average above the upper limit of the borderline group. The common method and the method of Cascallar and Cascallar (2003) both have a cut score of 25. Type I, type II, and type IV students score on average below the cutoff point. In general, type I students score below the borderline group while type II and type IV students score within the borderline group. Type III students score on average above the cut-off point, even above the borderline group.

\section{Discussion}

The present study investigated the effects of standard setting methods and verified whether there is one single standard setting method that discriminates best between the different types of students. This research studied the effect of different methods on the population of borderline students, which are students who score within a $95 \%$ confidence interval of the cut-off point, and the effect on the discrimination between the different types of students.

Observable differences in size of the borderline group were found for every method, however, a univocal difference between absolute, relative and mixed methods was not found. There are comparatively large deviations in size of the borderline group between the tests when the same method is used; except for the method grading on the curve, which results in a very small borderline group with both tests. The types of students based on the classification of Van de Watering (2006), in the borderline group and in the group of underachieving students within the borderline group differ for every method as well.

These findings raise the question "which method is in fact the best discriminator between the different types of students based on the typology of Van de Watering (2006)?" The method which discriminates best is defined as a method where type III students score on average above the cut-off point, type II and type IV students (norm students) score on average around the cut-off point (within borderline group) and type I students score on average below the cut-off point.

Results indicate that it is difficult to point out one method across tests as the best discriminator. Different aspects of the test, such as the level of difficulty of the test and the related test scores of students, may have an important influence. However, for these tests, based on the findings above, the method of Cascallar and Cascallar (2003) appears to be the best discriminator, although the method of De Groot (1964) and the absolute method with relative reference point also score reasonably well for both tests. These are two absolute methods and one mixed method. The absolute methods score reasonably well for both tests, since the level of difficulty of the tests is 'average'. But for relatively easy or relatively difficult tests, one can expect a different outcome.

This study indicates that one single method discriminating correctly for every test does not exist. Characteristics of the situation such as test type (open-ended vs. closed questions) and level of difficulty of the test have an important influence. The literature also shows a lack of agreement regarding the existence of one single appropriate method for all tests. Berk (1986) as well as Colton and Hecht (1981) advocate the method of Angoff (1971) to be the best choice of method. This method was not studied in this research, but the method we selected as 'the best discriminator' between different types of students', the method of Cascallar and Cascallar, can be interpreted as a variant of the Angoff method (1971). A report of the National Academy of Education (NAE, 1993) states that not one method leads to correct results. They recommend that the use of the Angoff method (1971) or any other item-judgment method to set achievement levels should be discontinued (Shepard, Glaser, Linn, \& Bohrnstedt, 1993). Jaeger (1989) also concludes that no agreement exists regarding one best method. The standard setting problem does not seem to have a unequivocal solution (Dousma \& Horsten, 1989; Dousma, Horsten, \& Brants, 1997).

In addition, the results indicated that for all the tests, $50-80 \%$ of the students in the borderline group succeed with one method but fail with another. These results are suggesting some new ideas, since we did not find one single study in the literature that focussed on the borderline group. It can be stated that different methods have different cut-off points but those differences are not all stable across tests.

A study of this kind that uses student types as a basis to study characteristics of the borderline group has not been performed up until now. However, Berk (1986) studied the discrimination between succeeding and failing students with different methods but not the quality of discrimination between different types of students. This study can therefore be seen as an extension of Berks' research (1986). Since this study was based on teachers' observations, a possible artefact could be the subjective categorization by teachers (regardless of the high interrater reliability of .95). However, Van de Watering (2006) has clearly stated several important criteria in advance (see typology). Therefore, it can be suggested that the probability of coincidence is strongly reduced. Another aspect which should be addressed with caution is the possibility of generalisation. This study involves only two tests of 'average difficulty' and only one group of participants. Applying different standard setting methods to tests which differ in difficulty level or to different student groups, might be an interesting topic for future research. Finally, the tests in this study were built on closed and open questions which could have muddled the results. However, this study was conducted in an authentic educational setting, meaning that those type of tests occurred in practice. Future research could focus on one type of questions and further clarify the suggested interaction between student type, type of test and different standard setting methods.

Situation characteristics such as type and level of test are revealed as important determinants when a particular standard setting method has to be chosen. In practice the common method is used the most to determine the cut-off point. This study indicates that this method is not always a good choice. Especially with very hard or very easy tests this method seems to be too rigid or not rigid enough, respectively. To come to the most appropriate standard setting method for a particular test, it is important to acquaint teachers with the different methods and inform them about the advantages and disadvantages. Future research could investigate advantages and disadvantages of the different standard setting methods.

\section{References}

Angoff, W. H. (1971). Scales, norms, and equivalent scores. In R. L. Thorndike (Ed.), Educational measurement (pp. 508-600). Washington, DC: American council on Education.

Berk, R. A. (1986). A consumer's guide to setting performance standards on criterionreferenced tests. Review of Educational Research, 56, 137-172.

Beuk, C. H. (1984). A method for researching a compromise between absolute and relative standards in examinations. Journal of Educational Measurement, 21, 147152.

Birenbaum, M., Breuer, K., Cascallar, E., Dochy, F., Dori, Y., Ridgway, J., et al. (2006). A learning integrated assessment system. Educational Research Review, 1(1), 61-67.

Cascallar, A. S., \& Cascallar, E. C. (2003). Setting standards in the assessment of complex performances: The optimized extended-response standard setting method. In M. Segers, F. Dochy, \& E. C. Cascallar (Eds.), Optimising new modes of assessment: In search of qualities and standards (pp. 247-266). Dordrecht: Kluwer Academic Publishers.

Cizek, G. J. (1996). Setting passing scores. Educational Measurement: Issues and Practice, 15(2), 20-31 
Claessens, S., \& Van de Watering, G. (2003). Verschillen tussen de perceptie van tutoren op de leerprestatie en de toetsprestatie van hun studenten [Differences between the perceptions of tutors on the learning achievement and test achievement of their students]. Tijdschrift voor Hoger Onderwijs, 21(3), 199-214.

Cohen-Schotans, J., Van der Vleuten, C. P. M., \& Bender, W. (1996). Een betere cesuur bij tentamens [A better cut-off point for exams]. Onderzoek van Onderwijs, 25, 54-55.

Colton, D. A., \& Hecht, J. T. (1981). A preliminary report on a study of three techniques for setting minimum passing scores. Paper presented at the annual meeting of the National Council on Measurement in Education, Los Angeles.

De Groot, A. D. (1964). De kernitem-methode voor de bepaling van de cesuur voldoende/onvoldoende [A core item method for the provision of the cut-off suffciently/insufficient]. Paedagogische Studiën, 41, 425-440.

Dousma, T., \& Horsten, A. (1989). Tentamineren [To examine]. Groningen: WoltersNoordhoff.

Dousma, T., Horsten, A., \& Brants, J. (1997). Tentamineren [To examine]. Groningen: Wolters-Noordhoff.

Downie, N. M. (1967). Fundamentals of measurement. New York: Oxford University Press.

Ebel, R. L. (1965). Marks and marking systems. In R. L. Ebel (Ed.), Essentials of educational measurement (pp. 396-443). Englewood Cliffs, NJ: Prentice-Hall.

Ebel, R. L. (1972). Marks and marking systems. In R. Ebel (Ed.), Essentials of educationa measurement (pp. 307-355). Englewood Cliffs, NJ: Prentice-Hall Inc.

Jaeger, R. M. (1982). An iterative structured judgment process for establishing standards on competency tests: Theory and application. Educational Evaluation and Policy Analysis, 4, 461-475.

Jaeger, R. M. (1989). Certification of student competence. In R. L. Linn (Ed.), Educationa measurement (Third edition, pp. 485-514). Washington, DC: American Council on Education and National Council on Measurement Education.

Jonsson, A., \& Svingby, G. (2007). The use of scoring rubrics: Reliability, validity and educational consequences. Educational Research Review, 2(2), 130-144.

Kane, M. (1994). Validating the performance standards associated with passing scores. Review of Educational Research, 64, 425-461.

National Academy of Education. (1993). Setting performance standards for student achievement. Stanford, CA: Author.

Nunnally, J. C. (1967). Psychometric theory. New York: McGraw-hill.

Shepard, L., Glaser, R., Linn, R., \& Bohrnstedt, G. (1993). Setting performance standards for student achievement. Stanford, CA: National Academy of Education.

Van de Watering, G. (1999). Cesuurbepalingsmethode, MT-onderwijs [Cut-off provision method, MT-education]. Maastricht: Universiteit Maastricht.

Van de Watering, G. (2006). Assessment in constructivist learning environments. Studies about perceptions and assessment in a constructivist learning environment in relation to students' study outcomes [Dissertation]. Maastricht: Datawyse.
Van de Watering, G., \& Van der Rijt, J. (2006). Teachers' and students' perceptions of assessments: A review and a study into the ability and accuracy of estimating the difficulty levels of assessment items. Educational Research Review, 1(2), 133-147.

Van de Watering, G., \& van der Rijt, J. (2003). Toetsanalyse reguliere bloktoets 1.1 "Inleiding" [Testanalysis regular blocktest 1.1 "Introduction"]. Maastricht: EDIT.

Wijnen, W.H.F.W.. (1971). Onder of boven de maat: Een methode voor het bepalen van de grens voldoende/onvoldoende bij studietoetsen [Above or beyond the standard: A method for the provision of the cut-off sufficiently/insufficient for study tests]. Amsterdam: Swets \& Zeitlinger.

Zieky, M. J. (2001). So much has changed: How the setting of cut-scores has evolved since the 1980s. In G. J. Cizek (Ed.), Setting performance standards (pp. 19-52). Mahwah, NJ: Lawrence Erlbaum.

Filip Dochy is professor of teaching and training and corporate training at the Centre for Research on Professional Development, Corporate Training and Lifelong Learning (K.U. Leuven), Belgium. In his research he concentrates on new learning and training environments, new modes of assessment on teaching, and trainers' lifelong learning in teacher training and corporate training settings. He is a former president of the European Association for Research on Learning \& Instruction (EARLI, www.earli.org) and editor of the Educational Research Review.

Eva Kyndt is a PhD student at the Centre for Research on Professional Development, Corporate Training and Lifelong Learning at the University of Leuven (K.U. Leuven) Belgium. She is doing her doctoral study on the influence of workload, task complexity and student characteristics on student approaches to learning. Her other research interests are talent management and workplace learning.

Marlies Baeten is a PhD student at the Centre for Research on Professional Development, Corporate Training and Lifelong Learning, University of Leuven (K.U. Leuven) Belgium. Her research topics are students' approaches to learning, new learning environments, and new modes of assessment. Her contribution to this article is supported by the Fund for Scientific Research Flanders (F.W.O. Vlaanderen).

Sofie Pottier has obtained a masters' degree in Educational Sciences at the University of Leuven (K.U. Leuven), Belgium. She wrote her master thesis on standard setting methods.

Marlies Veestraeten is a student at the University of Leuven who is doing a research internship at the Centre for Research on Professional Development, Corporate Training and Lifelong Learning. 